\title{
DÜBLIN
}

Technological University Dublin

ARROW@TU Dublin

2003-01-01

\section{A Novel Hybrid Inverted-L Antenna with Wide Bandwidth}

\author{
Max Ammann \\ Technological University Dublin, max.ammann@tudublin.ie
}

J. A. Evans

University of Manchester

$\mathrm{ZWu}$

University of Manchester

Follow this and additional works at: https://arrow.tudublin.ie/engschececon

\section{Recommended Citation}

Ammann, M., Evans, J. \& Wu, Z. (2003) A novel hybrid inverted-L antenna with wide bandwidth. ICAP 2003: Twelfth International Conference on Antennas and Propagation, U.K. Vol.2, pp.720-722. 31 March 3 April, 2003, doi:10.1049/cp:20030177

This Conference Paper is brought to you for free and open access by the School of Electrical and Electronic Engineering at ARROW@TU Dublin. It has been accepted for inclusion in Conference papers by an authorized administrator of ARROW@TU Dublin. For more information, please contact arrow.admin@tudublin.ie, aisling.coyne@tudublin.ie,gerard.connolly@tudublin.ie.

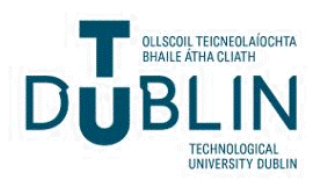




\title{
A NOVEL HYBRID INVERTED-L ANTENNA WITH WIDE BANDWIDTH
}

\author{
M. J. Ammann ${ }^{1}$, J. A. Evans ${ }^{1}$ and Z. Wu ${ }^{2}$
}

${ }_{2}^{1}$ Dublin Institute of Technology, Ireland

${ }^{2}$ University of Manchester, Institute of Science and Technology, UK

\begin{abstract}
The paper describes a novel inverted- $L$ antenna which comprises a short planar monopole loaded with two linear elements. This small antenna is shown to have impedance bandwidth up to $100 \%$ for $6 \mathrm{~dB}$ return loss. Antenna parameters such as impedance bandwidth, gain and pattern stability are examined and the measured data are in good agreement with a MoM/UTD analysis.
\end{abstract}

\section{INTRODUCTION}

Wideband antennas are becoming very attractive for future software-defined and reconfigurable wireless systems which may operate over multiple bands. The square planar monopole antenna has recently been proposed for these systems. The impedance bandwidth has been shown to be dependent on the feedgap separation [1] and recent attempts to improve the impedance bandwidth of this element include the use of annular slots, electromagnetic coupling, bevelling of the pianar element and the use of shorting posts [2-5]. The proposed hybrid Inverted-L Antenna (HILA) can be viewed as a short planar monopole loaded with two horizontal linear elements and a shorting strip. It overcomes the classical inherent narrow bandwidth and low input impedance of the ILA. This novel geometry operates in a hybrid mode; a transmission line mode exists in addition to the monopole mode, which greatly reduces the monopolar null depth. This is advantageous for mobile/wireless communications. The antenna is considerably smaller than a planar monopole and offers a much wider bandwidth than an ILA or planar inverted-F antenna.
Reducing the height of the planar monopole by folding has the disadvantage of reducing the bandwidth, but offers the advantages of smaller size and improved radiation characteristics. The antenna ultimately becomes a planar ILA as the height is reduced but we propose folding at $9 \%$ of a free-space wavelength where both modes exist.

\section{ANTENNA GEOMETRY}

The antenna was constructed using $0.2 \mathrm{~mm}$ thick copper sheet on a $100 \mathrm{~mm}$ square groundplane and fed using a SMA connector. The dimensions of the short planar monopole are $W=40 \mathrm{~mm}$ and $h=20 \mathrm{~mm}$ and a feedgap $g=2.5 \mathrm{~mm}$ was used. The length $l$, and width of the horizontal strips were $22 \mathrm{~mm}$ and $5 \mathrm{~mm}$, respectively. The antenna geometry and coordinate system is shown in Figure 1. The shorting strip dimension was $2 \mathrm{~mm} \times 2.5 \mathrm{~mm}$.

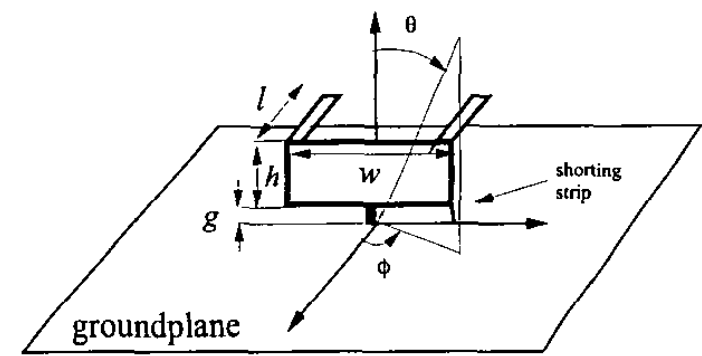

Figure 1. The antenna geometry and coordinate system. 


\section{EXPERIMENTAL RESULTS}

Impedance.

The return loss for the simple HILA (without shorting strip) was measured using an Anritsu vector network analyser and found to be greater than $6 \mathrm{~dB}$ (3:1 VSWR) from $1.62 \mathrm{GHz}$ to $3.85 \mathrm{GHz}$ and greater than $10 \mathrm{~dB}$ from $1.95 \mathrm{GHz}$ to 3.2 $\mathrm{GHz}$. The $6 \mathrm{~dB}$ bandwidth yield an $81 \%$ fractional impedance bandwidth. This is in good agreement with simulated results using a Method of Moments [7] technique augmented by the Uniform Theory of Diffraction [8]. The measured and simulated plots are shown in Figure 2.

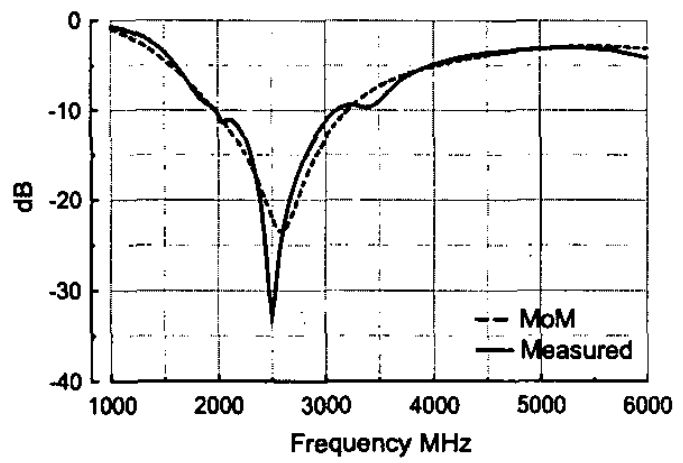

Figure 2. Measured and simulated return loss for the hybrid ILA.

The addition of a shorting strip $(2.5 \mathrm{~mm} \times 2 \mathrm{~mm})$ from one corner of the planar monopole to the groundplane yielded a reduced lower edge frequency, but caused a small bump in the swept retum loss curve, in the region $2.0 \mathrm{GHz}$ to 2.25 $\mathrm{GHz}$, where the return loss was a little less than $10 \mathrm{~dB}$. This can be seen in figure 3. The return loss was found to be greater than $6 \mathrm{~dB}$ from 1.25 $\mathrm{GHz}$ to $3.9 \mathrm{GHz}$ (>100\% fractional impedance bandwidth) and the $10 \mathrm{~dB}$ bandwidth was 1.38 $\mathrm{GHz}$ to $3.55 \mathrm{GHz}$ (except for the bump). The return loss is also greater than $6 \mathrm{~dB}$ in the region $5.2 \mathrm{GHz}$ to $6 \mathrm{GHz}$. This makes the antenna suitable for multiband wireless LANs operating on $2.400-2.483 \mathrm{GHz}$ and the 5.15-5.25, 5.25-5.35, 5.47-5.725 and 5.725-5.875 GHz bands $(802.11 \mathrm{~b}$, g, a, UNII and HiperLAN 2). The height of $20 \mathrm{~mm}$ represents $8.3 \%$ and $9.5 \%$ of a free-space wavelength at the $6 \mathrm{~dB}$ and $10 \mathrm{~dB}$ return loss lower edge frequencies, respectively.

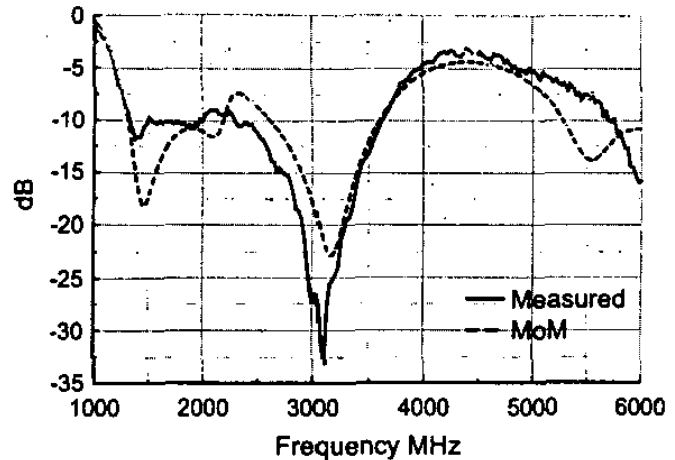

Figure 3. Measured and simulated return loss for the hybrid ILA with shorting strip

Radiation pattern.

The radiation patterns were measured at $1.5 \mathrm{GHz}$ and $3.6 \mathrm{GHz}$, which are close to the upper and lower edge frequency of the impedance bandwidth. The measured patterns for the simple HILA in the $H$ plane $(\phi, \theta=90)$ are shown in Figure 4 and illustrate an omnidirectional pattern at the lower frequency and a quasi omnidirectional pattern at $3.6 \mathrm{GHz}$. The measured pattern for the shorted HILA is shown in Figure 5 and again shows an omnidirectional pattern at $1.5 \mathrm{GHz}$ but the pattern at $3.6 \mathrm{GHz}$ shows noticeable distortion with deep nulls.

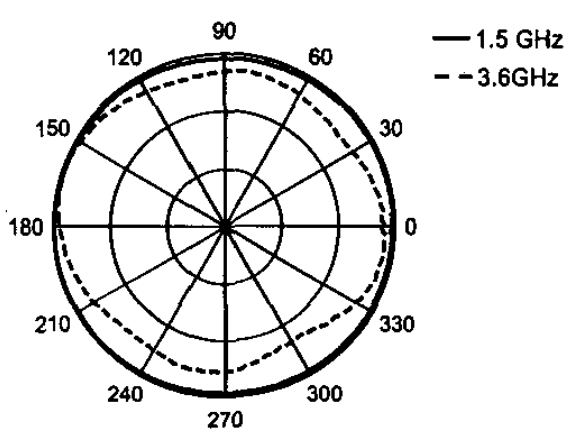

Figure 4. H-plane pattern for the simple HILA 


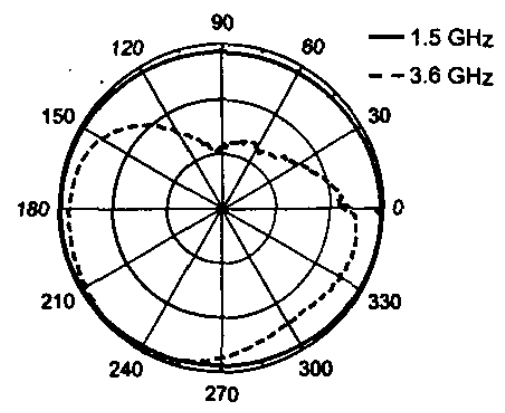

Figure 5. H-plane pattern for the shorted HILA

The E-plane $(\theta, \phi=0)$ patterns are shown in Figures 6 and 7 , for the simple HILA and the shorted HILA respectively. The pattern for the simple HILA demonstrates a significantly reduced monopolar null, of $6 \mathrm{~dB}$ and $2 \mathrm{~dB}$ at $1.5 \mathrm{GHz}$ and $3.6 \mathrm{GHz}$ respectively. The shorted HILA pattern again differs only at the higher frequency but maintains a reduced monopolar null of $5 \mathrm{~dB}$ and 3 $\mathrm{dB}$ respectively.

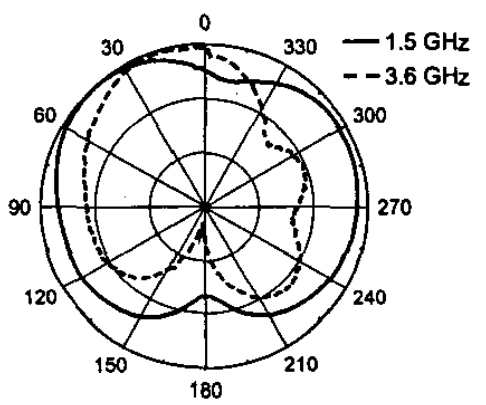

Figure 6. E-plane pattern for the simple HILA

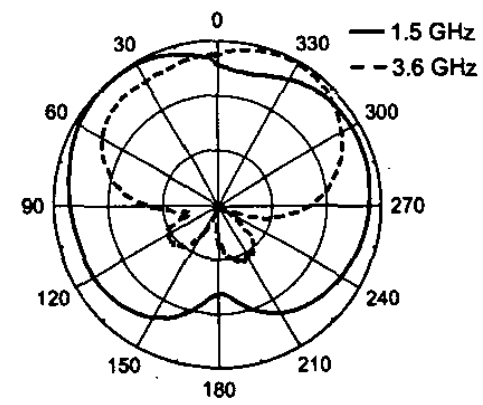

Figure 7. E-plane pattern for the shorted HILA
The maximum value of measured gain for the simple HILA was found to be $4.1 \mathrm{dBi}$ and $5.2 \mathrm{dBi}$ at $1.5 \mathrm{GHz}$ and $3.6 \mathrm{GHz}$ respectively. The effect of the shorting strip on maximum gain was minimal $(< \pm 1 \mathrm{~dB})$

\section{CONCLUSIONS}

A hybrid inverted-L antenna which comprises a short planar monopole loaded with two linear elements has been investigated. The antenna shows wideband characteristics with good pattem stability. The addition of a shorting strip increases the impedance bandwidth at the expense of pattern stability. The antenna is proposed for modern wireless applications which operate over multiple bands.

\section{REFERENCES}

1 Ammann, M. J., 'Square Planar Monopole Antennas, 1999, IEE NCAP, York, UK, pp. 37-40.

2 Chen, Z.N, Ammann, M .J and Chia, M.Y.M, 2002, Annular Circular Planar Monopole Antennas, IEE Proceedings MAP, 149, (4), pp. 200-204.

3. Chen, Z. N., 2000, 'Broadband planar monopole antenna, IEE Proceedings, MAP 147, (6), pp. 526-528.

4. Ammann, M. J., 2001, 'The pentagonal planar monopole for digital mobile. terminals: bandwidth considerations and modelling, $11^{\text {th }}$ ICAP 1, pp. 82-85.

5. Lee, L. S., Hall P. S. and Gardner, P. 1999, 'Compact wideband planar monopole antenna Electronics Letters. 35, pp. 2157-2158.

6. Harrington, R. F., 1968, Matrix Methods for Field Problems, Macmillan, New York.

7. Kouyoumijan, R. G and Pathak, P., 'A Uniform Theory of Diffraction for an Edge in a perfectly Conducting Surface 1974, Proc. IEEE, 62, (11), 1448-1461. 